\title{
Spinal cord haemorrhage following herpes zoster: a possible complication of warfarin therapy
}

\author{
Michael L. FriedLAND* \\ M.D. \\ EDWARD G. WiTTELS $\dagger$ \\ M.D. \\ The * Section of Medicine, Brown University, and the †Division of Hematology-Oncology, \\ Department of Medicine, The Miriam Hospital, Providence, Rhode Island, USA.
}

\begin{abstract}
Summary
Haemorrhage is the most serious and common sideeffect of warfarin therapy. Bleeding has commonly been observed in the gastrointestinal and genitourinary tracts as well as in the skin and subcutaneous tissue. Central nervous system bleeding has also been reported and has usually been associated with marked prolongation of the prothrombin time. Spinal cord haemorrhage has been infrequently observed. The patient reported here may represent a previously undescribed complication of herpes zoster infection with haemorrhage in the involved dorsal root ganglia. Possible mechanisms are discussed.
\end{abstract}

\section{Introduction}

The most serious toxic effect of warfarin therapy is haemorrhage. Its occurrence has been estimated as ranging between $0.25 \%$ and $23 \%$ of anticoagulated patients (Pastor, Resnick and Rodman, 1962; Pollard et al., 1962). The incidence is directly proportional to the degree of prolongation of the prothrombin time. Frequently, areas with occult pathology, especially the gastrointestinal and genitourinary tracts, will be the site of bleeding (Zweifler, Coon and Willis, 1966). Other sites such as skin and subcutaneous tissues can undergo haemorrhagic infarction (Dahadir, James and Feede, 1977). This case report describes a patient who developed a spinal cord haemorrhage within the distribution of a herpes zoster infection while receiving warfarin therapy.

\section{Case report}

This 68-year-old woman developed herpes zoster affecting T8-10 on the right side of her body 3 weeks before admission. At the same time, a mass was also noted in the left breast, a biopsy of which revealed adenocarcinoma. She underwent a left radical mastectomy. During the postoperative period she experienced a pulmonary embolus which was treated initially with heparin and subsequently warfarin. She was discharged on warfarin, $5 \mathrm{mg}$ daily. Before discharge her prothrombin time ranged between 17-20 sec (control 11-12 sec). Her only other discharge medications included ferrous sulphate and erythromycin. On the day of admission she noted the sudden onset of weakness in her right leg, associated with a general feeling of weakness and inability to urinate. Neurological findings included weakness and decreased sensation of the right leg and an absent anal reflex. A spinal tap and thoracic myelogram were performed which demonstrated grossly bloody cerebrospinal fluid and a complete extra-medullary block at T11-12. At that time her prothrombin time was $27 \mathrm{sec}$ (control 11 $\mathrm{sec}$. Following correction of her prothrombin time with fresh frozen plasma and vitamin $K$, she underwent a thoracic laminectomy which revealed a dark blue haematoma extending from T6-T12. The patient experienced a satisfactory decompression but was left with a paresis of the right lower extremity.

\section{Discussion}

Intracranial bleeding apparently induced by oral anticoagulants is well described and reported. Wells and Urrea (1960) noted 3 bleeding sites including intracerebral, subdural and extra-dural haematomas. Intraspinal haemorrhage has also been observed. Lilly and Lee (1949) reported one such episode following lumbar puncture and Arieff and Pyaek (1954) and Busse (1972) noted cases of spontaneous spinal cord haemorrhage in patients whose prothrombin time was markedly prolonged. Macon, Morton and Adams (1970) in their review suggested that straining, coughing or trauma may be factors which initiate the haemorrhage. No evidence of trauma could be elicited in the present patient and the prothrombin time was within the therapeutic range. The authors propose another mechanism for haemorrhage, i.e. the development of herpes zoster infection with subsequent bleeding near the involved ganglia. Often in herpes zoster, one dorsal root 
ganglion is involved but adjacent ganglia also are known to demonstrate pathological changes, albeit less severe. In the acute stage of zoster infection the affected ganglion generally is swollen, congested and often haemorrhagic in appearance (Blackwood and Corsellis, 1976). Necrosis may occur. In approximately $5 \%$ of cases motor neurone involvement also occurs (Blackwood and Corsellis, 1976).

In the anticoagulated patient this pathological process could effect a haemorrhage arising in the involved region of the spinal cord with the production of the clinical and pathological findings observed.

\section{References}

Arieff, A. \& Pyaek, S.W. (1954) Paraplegia following or associated with excessive dicumarol therapy. Quarterly Bulletin of Northwestern University Medical School, 28, 221.

BlaCkwood, W. \& CoRsellis, J.A.N. (1976) In: Greenfield's
Neuropathology, 3rd edn, p. 301. Edward Arnold, Edinburgh.

Busse, O. (1972) Spontaneous epidural spinal haematoma during and following anticoagulant medication. Nervenarzt, 43, 318.

Dahadir, I., James, E.C. \& Feede, C.W. (1977) Soft tissue necrosis and gangrene complicating treatment with the coumarin derivatives. Surgery, 145, 497.

LiLlY, G.D. \& LEE, R.M. (1949) Complication of anticoagulant therapy. Surgery, 26, 957.

Macon, W.L., Morton, J.H. \& Adams, J.T. (1970) Significant complications of anticoagulant therapy. Surgery, 68, 571.

Pastor, B.H., Resnick, M.E. \& Rodman, T. (1962) Serious hemorrhagic complications of anticoagulant therapy. Journal of the American Medical Association, 180, 747.

Pollard, J.W., Hamilton, M.J., Christensen, N.A. \& ACHA, R.W. (1962) Problems with long-term anticoagulant therapy: observations in 139 cases. Circulation, 25, 311.

Wells, C.E. \& URReA, D. (1960) Cerebrovascular accidents in patients receiving anticoagulant drugs. Archives of Neurology, 3, 553.

ZWeifler, A.J., CoON, W.W. \& Willis III, P.A. (1966) Bleeding during oral anticoagulant therapy. American Journal of Hematology, 71, 119. 